\title{
CONJUGATION REACTIONS IN THE NEWBORN INFANT: THE METABOLISM OF PARA-AMINOBENZOIC ACID
}

\author{
BY \\ MARKUS F. VEST* and RENÉ SALZBERG \\ From the Children's Hospital, University of Basel, Switzerland
}

(RECEIVED FOR PUBLICATION JULY 8, 1964)

It has been shown that the liver of the newborn infant has a limited capacity to perform certain transformation or conjugation reactions when compared to older subjects (Driscoll and Hsia, 1958; Kretchmer, Levine, McNamara, and Barnett, 1956). This limitation is evident in the formation of glucuronides (Brown and Zuelzer, 1958; Vest, 1958) and plays an important role in the genesis of neonatal jaundice. There are indications that other conjugation or detoxification mechanisms are also carried out in a different way from that of later life. The observation that after administration of sodium benzoate the excretion as hippuric acid is incomplete and delayed during the first three to four months of life (Vest, 1959) prompted us to investigate hippurate formation and acetylation in this age period.

\section{Material and Methods}

Para-aminobenzoic acid (PAB) in the form of the sodium salt $(\mathrm{NaPAB}) \dagger$, was injected intravenously in a dose of $100 \mathrm{mg}$. per $\mathrm{kg}$. body weight into four children 8 to 11 years old, three newborn premature infants of 2 to 6 days, two newborn full-term infants, and two 5- and 8 -week-old infants. All subjects were male. Fluid intake was not restricted during the test.

Blood, 1-2 ml., was collected 5, 15, and 30 minutes, 1, 2, 3,4 , and, if necessary, 6 and 8 hours after the administration of the test dose. Urine was collected over 24 hours, divided in three 4-hour and a final 12-hour period. The urine was kept at $4^{\circ} \mathrm{C}$. when assayed within a few hours, otherwise it was frozen at minus $20^{\circ} \mathrm{C}$.

The sodium-p-aminobenzoate solution for intravenous use was prepared as follows: $10 \% \mathrm{NaPAB}$ was dissolved in distilled water $(w / v)$. The water was boiled before use and nitrogen bubbled through to remove carbon dioxide; $10 \mathrm{ml}$. amounts were put into brown ampoules which were filled with nitrogen just before sealing. The ampoules were sterilized by autoclaving at $120^{\circ} \mathrm{C}$. for a quarter of an hour.

* Address: Children's Hospital, Römergasse 8, Basel, Switzerland. † Fluka, Buchs.
The method of Deiss and Cohen (1950) was uscd for the estimation of PAB and para-aminohippuric acid (PAH). PAH was estimated after extraction of PAB with ether. After extracting mixtures of known composition, on the average $1 \% \mathrm{PAB}$ and $98 \%$ PAH remained. For the estimation of acetylated PAB and PAH (acetamido-benzoic and acetamido-hippuric acid + ) in the serum aliquots of the deproteinized supernatant were hydrolysed by boiling with 0.05 volume of $4 \mathrm{~N} \mathrm{HC1}$ for 20 minutes. In the case of urine better results were obtained by hydrolysing for 45 minutes. In some experiments the hydrolysis of acetylated compounds was carried out by heating at $96^{\circ} \mathrm{C}$. for three and a half hours as suggested by Smith, Finkelstein, Aliminosa, Crawford, and Graber (1945). After addition of the diazo reagents, the samples were read against a reagent blank at $540 \mathrm{~m} \mu$ in a Coleman junior spectrophotometer. The amounts were determined from a calibration curve made with various concentrations of PAH. All results are expressed in micromols $(\mu \mathrm{M})$ of PAH.

The colour intensity obtained without hydrolysis is equal to the free PAB and PAH. By extracting PAB, PAH alone can be measured. After hydrolysis the colour development is equal to the sum of PAH, PAB, and acetylated compounds. From this value the amount of total acetyl-metabolites (acetylated PAB and PAH) can be calculated by subtracting free PAB and PAH. Acetylated PAH is found by extracting the hydrolysate with ether (which removes the free and the formerly acetylated PAB) and subtracting the value of free PAH.

In two infants and one child the urinary metabolites were separated by counter-current distribution techniques. With each plate $5 \mathrm{ml}$. ethyl acetate was used as organic, and $5 \mathrm{ml} .1 \cdot 6 \mathrm{M}$ acetate buffer $p \mathrm{H} \mathrm{3 \cdot 4}$, as aqueous phase (Way, Smith, Howie, Weiss, and Swanson, 1948; Tabor, Freeman, Baily, and Smith, 1951). 50 to 100 plate distributions were run and both layers analysed for PAB, PAH, acetylated PAB and PAH, and glucuronides. For analysis the organic layer was first taken to dryness. A drop of ethanol facilitated dissolving the residue in water. The acetate phase was analysed directly. Glucuronide was estimated by the carbazole method of Dische (1947).

‡ Roche, Basel. 

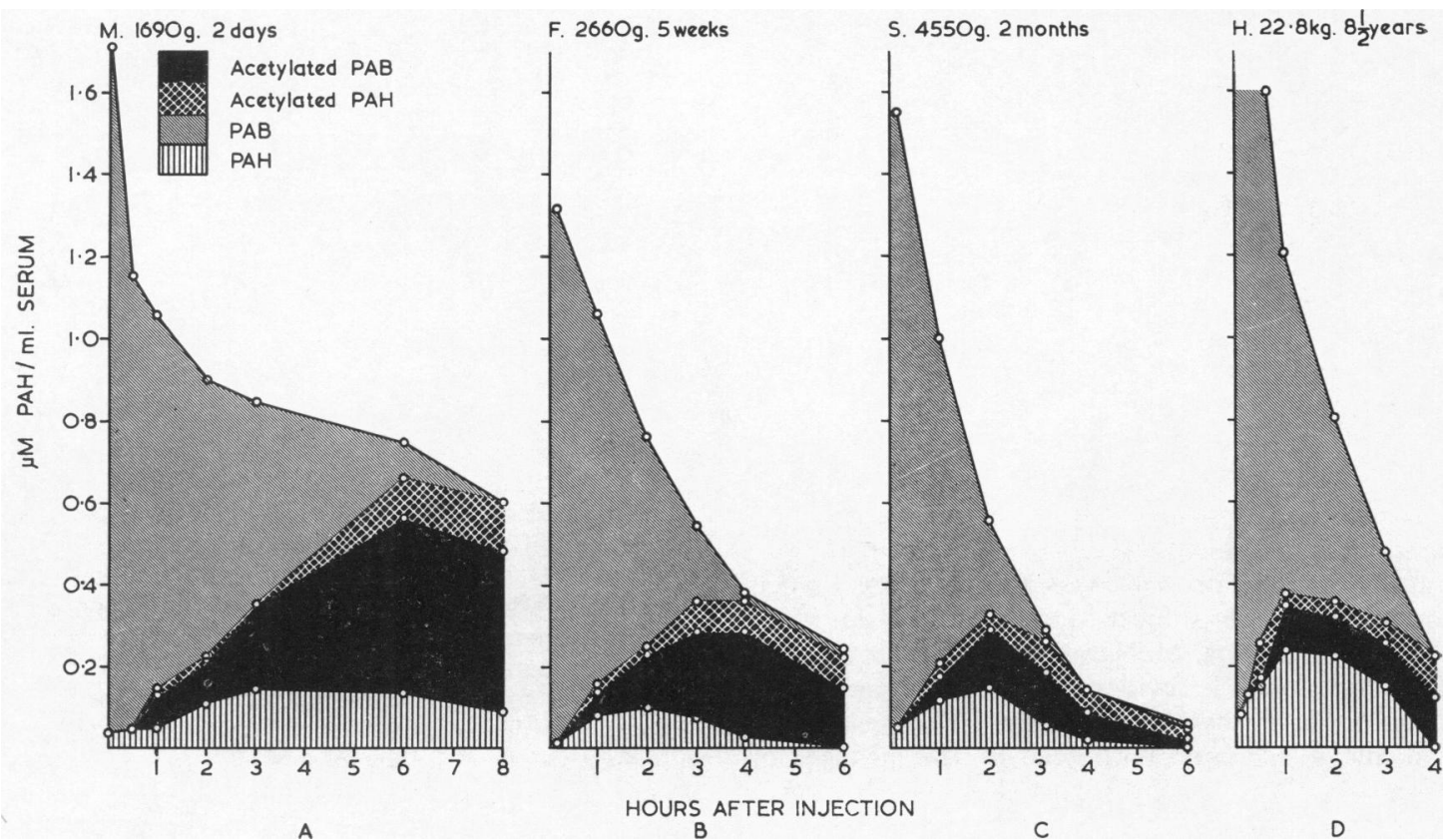

FIG. 1.-Concentration of p-aminobenzoic acid (PAB) metabolites in the serum after intravenous injection of 100 mg. sodium p-aminobenzoate per kg. body waight. All values are expressed as $\mu \mathrm{M}$ p-aminohippuric acid per $1 \mathrm{ml}$. serum.

(A) newborn infant, (B) infant 5 weeks old, (C) infant 2 months old, (D) child $8 \frac{1}{2}$ years.

The identity of the urinary metabolites separated by counter-current distribution was studied by running aliquots on paper chromatograms. An ascending system of butanol-glacial acetic acid and water in the proportions $4: 1: 2(\mathrm{v} / \mathrm{v})$ was used with Whatman No. 1 paper. Standards of PAH, PAB, acetylated PAH, and acetylated PAB were run simultaneously. Ehrlich reagent (pdimethylaminobenzaldehyde, $10 \%$ in concentrated $\mathrm{HC} 1$ solution (w/v) 1 vol., acetone 4 vol.) gave an immediate yellow colour with PAB, PAH, and PAB-glucuronide. With acetylated PAB and PAH the colour development was delayed. Compounds with a free amino group can also be distinguished from the acetylated metabolites by the Ekman reagent specific for diazotizable amines. Glucuronyl derivatives were identified by the napththoresorcinol and aniline-diphenylamine reagent (Smith, 1960).

\section{Results}

PAB Metabolites in the Serum. Fig. 1 shows typical examples of the course of the various PAB acid metabolites in the serum in the different agegroups. In the 2-day-old premature infant (Fig. 1A) free PAB disappears slowly from the circulation. $\mathrm{PAH}$ is the first conjugate to appear. It reaches a peak of $0.12 \mu \mathrm{M}$ per ml. serum 3 hours after injection of NaPAB. Acetylated PAB is the chief conjugate formed. It reaches a peak concentration of up to $0.6 \mu \mathrm{M}$ per ml. at 6 hours. Besides PAH and acetyl-PAB small amounts of acetylated p- aminohippuric acid are formed. This conjugate is the last to appear in significant amounts.

Compared to the newborn infants, free PAB decreases quicker in the 5-week-old and more so in the 2-month-old infant (1B and C). At an age of 5 weeks acetyl-PAB is still the major conjugate formed (Fig. 1B). In the 2-month-old infant PAH formation is more prominent, though it is still less than that found in older children (Fig. 1C). Acetylated PAB is present to a greater degree than in older children, but much less than at 5 weeks. Some acetylated PAH is also present. In the $8 \frac{1}{2}$-yearold child (Fig. 1D) there is a rapid decrease of free PAB. The major conjugate now is PAH which reaches a peak of $0.25 \mu \mathrm{M}$ per $\mathrm{ml}$. at 1 hour. Acetyl-PAB appears later and its concentration remains lower than that of PAH. Some acetylPAH is also present. Both acetylated metabolic products are still present 4 hours after injection, when PAB and PAH have already disappeared. No attempt has been made to investigate glucuronide conjugation in the serum.

Fig. 2 shows the average plasma disappearance curves of total PAB metabolites at different ages. In the newborn period it is rather flat; at 8 weeks it reaches the slope found in older children. The 5-week-old infant takes an intermediate position. 


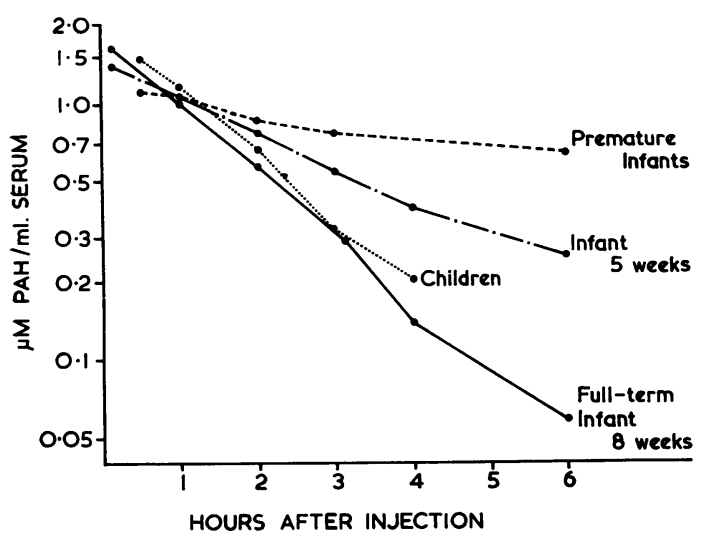

Fig. 2.-Rate of disappearance of total PAB from plasma in the newborn period, in infants and in children after intravenous injection of sodium p-aminobenzoate.

The time elapsing until the plasma concentration of total PAB has fallen to $50 \%$ of the initial level, is about 6 hours for the newborns, 3 hours 40 minutes in the 5-week-old infant, and 1 hour and $\mathbf{4 0}$ minutes in the 8-week-old infant and in the children.

PAB Metabolites in the Urine. The excretion of PAB derivates in the urine reflects the situation in the serum. In Fig. 3 the cumulative urinary excretion of the 4 metabolites is given as a percentage of the injected dose of sodium PAB for the same children whose serum concentrations are shown in Fig. 1. In the newborn infant (Fig. 3A), the metabolites appear slowly. After 4 hours only about $10 \%$ of the given PAB is excreted. In the serum (Fig. 1A) the PAH formed has been largely excreted after 6 to 8 hours. The same is evident in the cumulative urinary excretion, i.e. after 8 to 12 hours the amount excreted as PAH hardly increases any further. The chief metabolites, acetylated PAB and PAH on the other hand, appear more slowly and are excreted predominantly between 8 to 24 hours. Free PAB accounts for less than $7 \%$ of the total excreted.

Fig. 3B and $\mathrm{C}$ show the transition from the pattern prevailing in the newborn period to the one later in childhood. Not only does the total 24-hour recovery increase but the excretion accelerates. In the 5-week-old infant the chief metabolites are still acetyl-PAB and -PAH, but at 8 weeks PAH is the major conjugate. Even at this age however, much more acetyl-PAB is excreted than later in life.

In the child (Fig. 3D), the excretion is much more rapid, so that 70 to $85 \%$ is recovered within 4 hours after injection. The chief conjugate is p-aminohippuric acid, which accounts for about $50 \%$ of the total PAB recovered. Free p-aminobenzoic acid generally takes the second place. Acetylated p-aminohippuric acid accounts for less than $10 \%$ of the recovered PAB.

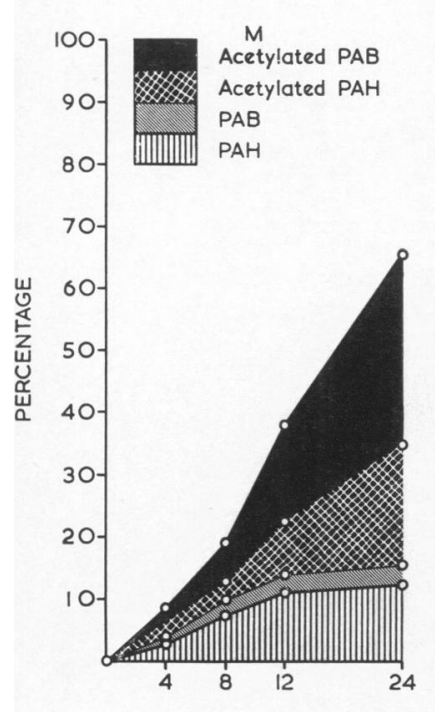

A

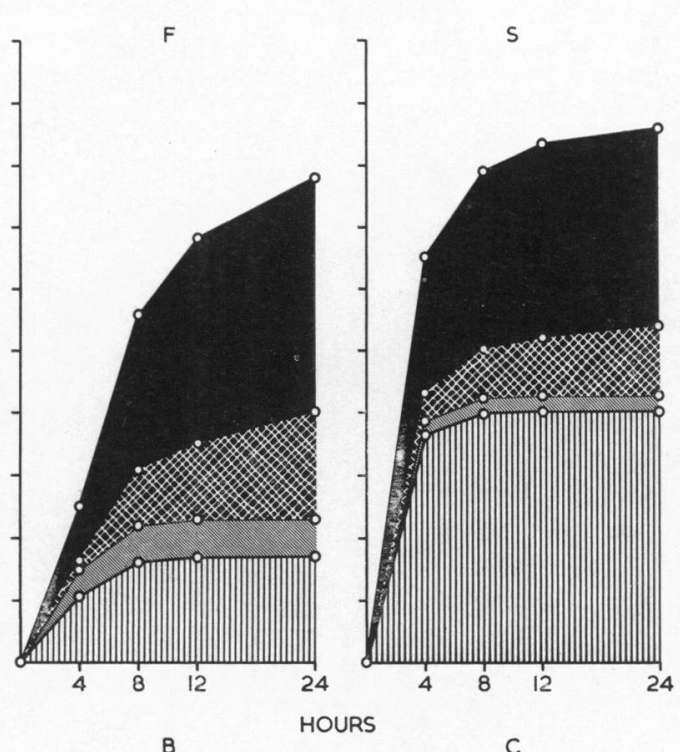

B

C

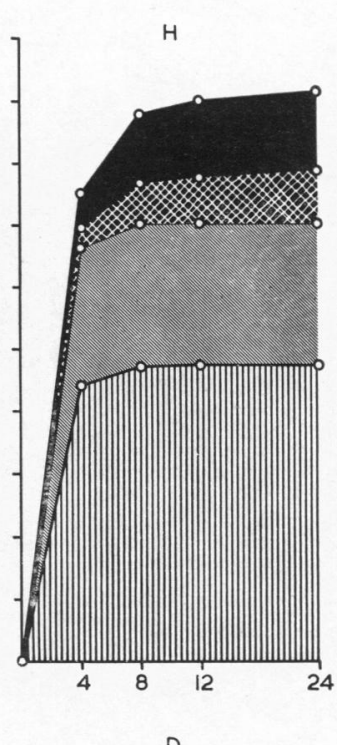

D

FIG. 3.-Cumulative 24-hour urinary excretion of the various PAB metabolites in percentage of the given dose of PAB. (A) newborn infant, (B) infant 5 weeks old, (C) infant 2 months old, (D) child $8 \frac{1}{2}$ years. 
TABLE 1

PERCENTAGE DISTRIBUTION OF THE DIFFERENT PAB DERIVATIVES IN THE URINE IN RELATION TO AGE-GROUPS

\begin{tabular}{|c|c|c|c|c|c|c|c|}
\hline Name & Age & $\begin{array}{l}\text { Total 24-hour } \\
\text { Recovery (\%) }\end{array}$ & PAH (\%) & $\operatorname{PAB}(\%)$ & $\begin{array}{c}\text { Acetyl } \\
\text { PAH }(\%)\end{array}$ & $\begin{array}{c}\text { Acetyl } \\
\text { PAB ( } \%)\end{array}$ & $\underset{(\%)}{\text { Glucuronides }}$ \\
\hline $\begin{array}{c}\text { Premature new- } \\
\text { borns } \\
\text { M.P. } \\
\text { Sch. A. } \\
\text { L.R. }\end{array}$ & $\begin{array}{l}2 \text { days } \\
4 \text { days } \\
6 \text { days }\end{array}$ & $\begin{array}{l}65 \cdot 2 \\
47 \cdot 7 \\
70 \cdot 6\end{array}$ & $\begin{array}{l}12 \cdot 8 \\
14 \cdot 6 \\
10 \cdot 2\end{array}$ & $\begin{array}{l}2 \cdot 5 \\
1 \cdot 4 \\
5 \cdot 9\end{array}$ & $\begin{array}{l}19 \cdot 2 \\
15 \cdot 5 \\
21 \cdot 1\end{array}$ & $\begin{array}{l}30 \cdot 7 \\
16 \cdot 2 \\
33 \cdot 4\end{array}$ & $\begin{array}{l}7 \cdot 9 \\
7 \cdot 7 \\
6 \cdot 2\end{array}$ \\
\hline Mean & & $61 \cdot 1$ & $12 \cdot 5$ & $3 \cdot 2$ & $18 \cdot 6$ & $26 \cdot 7$ & $7 \cdot 2$ \\
\hline $\begin{array}{c}\text { Full-term new- } \\
\text { borns } \\
\text { M.R. } \\
\text { A.D. } \\
\text { Infants } \\
\text { F.R. } \\
\text { S.J. }\end{array}$ & $\begin{array}{l}3 \text { days } \\
5 \text { days } \\
5 \text { wk. } \\
8 \text { wk. }\end{array}$ & $\begin{array}{l}72 \cdot 8 \\
62 \cdot 3 \\
78 \cdot 4 \\
85 \cdot 6\end{array}$ & $\begin{array}{l}29 \cdot 0 \\
24 \cdot 5 \\
16 \cdot 9 \\
39 \cdot 4\end{array}$ & $\begin{array}{l}2 \cdot 2 \\
2 \cdot 3 \\
6 \cdot 0 \\
1 \cdot 9\end{array}$ & $\begin{array}{l}20 \cdot 5 \\
12 \cdot 2 \\
17 \cdot 0 \\
11 \cdot 7\end{array}$ & $\begin{array}{l}21 \cdot 1 \\
23 \cdot 3 \\
38 \cdot 5 \\
32 \cdot 6\end{array}$ & $\begin{array}{l}23 \cdot 5 \\
13 \cdot 7 \\
16 \cdot 9 \\
21 \cdot 9\end{array}$ \\
\hline $\begin{array}{l}\text { Children } \\
\text { H.B. } \\
\text { P.C. } \\
\text { E.J. } \\
\text { C.J. }\end{array}$ & $\begin{array}{c}8 \frac{1}{2} \text { yr. } \\
9 \text { yr. } \\
10 \mathrm{yr} . \\
11 \mathrm{yr} .\end{array}$ & $\begin{array}{l}90 \cdot 9 \\
76 \cdot 0 \\
88 \cdot 4 \\
93 \cdot 6\end{array}$ & $\begin{array}{l}47 \cdot 1 \\
42 \cdot 0 \\
49 \cdot 8 \\
50 \cdot 0\end{array}$ & $\begin{array}{r}22 \cdot 3 \\
17 \cdot 0 \\
15 \cdot 8 \\
7 \cdot 9\end{array}$ & $\begin{array}{r}8 \cdot 8 \\
4 \cdot 0 \\
11 \cdot 1 \\
8 \cdot 9\end{array}$ & $\begin{array}{l}12 \cdot 7 \\
13 \cdot 0 \\
11 \cdot 7 \\
26 \cdot 8\end{array}$ & $\begin{array}{l}15 \cdot 7 \\
19 \cdot 4 \\
14 \cdot 2 \\
17 \cdot 9\end{array}$ \\
\hline Mean & & $87 \cdot 2$ & $47 \cdot 2$ & $15 \cdot 7$ & $8 \cdot 2$ & $16 \cdot 0$ & $16 \cdot 8$ \\
\hline
\end{tabular}

Glucuronic Acid Conjugates. Because glucuronic acid conjugates are present in the urine even without PAB administration, it is difficult to estimate the percentage of $\mathrm{PAB}$ glucuronides accurately. If the quantity of glucuronic acid found in a 24-hour urine sample before the test is subtracted from the amount found after PAB injection, it is possible to get an estimate of the percentage of PAB excreted as a glucuronyl conjugate. As will be shown later two glucuronyl conjugates, p-aminobenzoyl- and p- acetamido-benzoyl glucuronide, are present in various proportions depending on age. Because their solubility is not very different from that of the glycine conjugates, they stay behind when PAB is extracted. In the colorimetric assay these conjugates are therefore estimated along with PAH and acetylPAH respectively. They can, however, be measured separately by the Dische (1947) method. Analysis of the consecutive urine samples shows that in the newborn the glucuronides follow the same course as

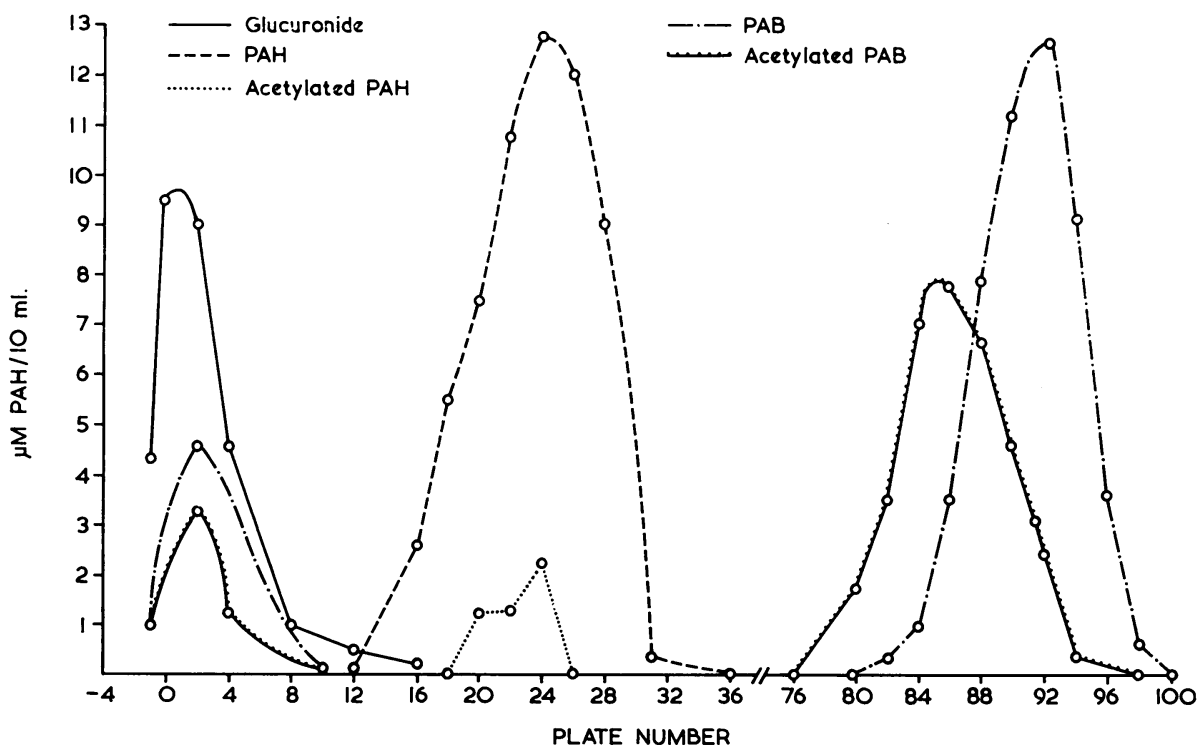

FIG. 4.-Result of a 100 plate counter-current distribution of an aliquot of the first 4-hour urine sample in a 10-year-old child after intravenous PAB injection. The concentration of the various metabolites is given as $\mu \mathrm{M}$ PAH per plate. 


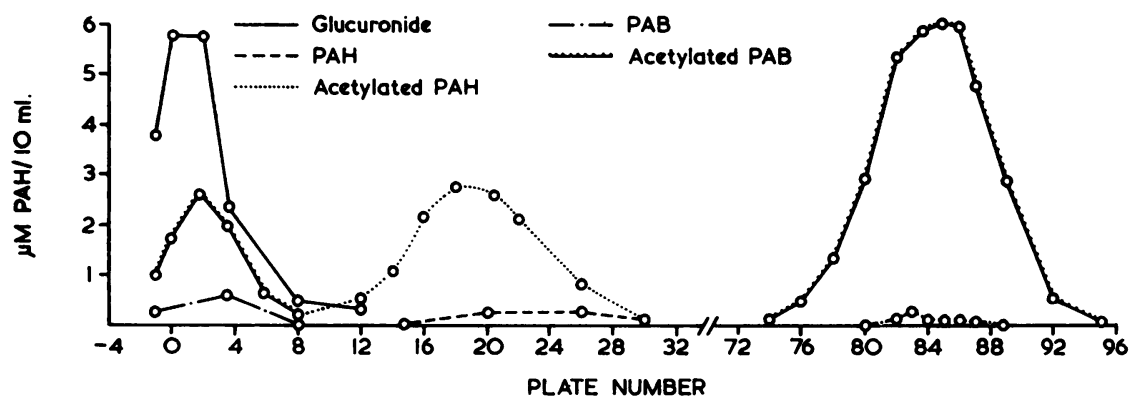

Fig. 5.-Newborn infant. Result of a 95-plate counter-current distribution of a urine sample collected from 8 to 24 hours after intravenous PAB injection.

the other PAB conjugates, i.e. they appear much slower than in the group of children.

In Table 1 the percentage of the various PAB derivatives in the urine is given for the different agegroups. The value for the glucuronides is given separately but is already included in the column headed Total 24-hour Recovery, because, as mentioned above, they form a part of PAH and acetyl-PAH.

Separation of PAB Metabolites by Counter-current Distribution. Fig. 4 shows the results of the countercurrent distribution in a 10-year-old child. A distribution of an aliquot of the first four-hour urine sample was run. A complete separation of PAH from acetyl-PAH and of PAB from acetyl-PAB could not be achieved, but the glucuronides were clearly separated from PAH and acetyl-PAH respectively and the latter from $P A B$ and acetylPAB. The results agree with those obtained by colorimetric estimation. The chief metabolite present is PAH, with free PAB, acetylated PAB, and acetylated PAH following in decreasing order. There are two glucuronic acid conjugates: $P A B-$ and acetyl-PAB-glucuronide. These do not quite account for all the glucuronic acid in the first plates. This is to be expected as other glucuronides are present in the urine. Planimetry of the curve results in the following percentage distribution:
PAH $36 \cdot 7$, acetyl-PAH $2 \cdot 7$, PAB $28 \cdot 8$, acetyl-PAB $19 \cdot 4$, p-aminobenzoyl glucuronide $7 \cdot 7$, and acetamidobenzoyl glucuronide $4 \cdot 7$.

The result in a newborn infant is shown in Fig. 5. It was obtained from an aliquot of the urine collected from 8 to 24 hours and confirms the predominance of acetylated PAB and acetylated PAH over PAH, and the presence of PAB-glucuronides. In contrast to older children, $p$-acetamidobenzoyl glucuronide, not p-aminobenzoyl glucuronide is the main glucuronic acid conjugate in infants. The percentage distribution is as follows: PAH $3 \cdot 7$, acetyl-PAH $26 \cdot 7$, PAB $0 \cdot 7$, acetyl-PAB $54 \cdot 8$, p-aminobenzoyl glucuronide $2 \cdot 2$, acetamidobenzoyl glucuronide $11 \cdot 9$.

In Table 2 the ratio of distribution of the four standard compounds between ethyl acetate and buffer is compared to that calculated from the counter-current distribution. They agree only to a limited extent.

Chromatography of PAB Metabolites. Fig. 6 shows a chromatogram of the main peaks obtained by counter-current distribution in child E. J. Plate No. 24 has the same value (Rf 0.62 ) as PAH, 81 as acetyl-PAB (Rf $0 \cdot 89$ ), and 97 as $P A B(R f 0 \cdot 83)$. In No. 2, which gives the highest reading for glucuronic acid, there are two spots the $\mathrm{Rf}$ values of which are

TABLE 2

RATIO OF DISTRIBUTION BETWEEN ETHYL ACETATE AND ACETATE BUFFER OF PAB AND DERIVATIVES COMPARED WITH DISTRIBUTION CONSTANTS OBSERVED IN COUNTER-CURRENT DISTRIBUTION

\begin{tabular}{|c|c|c|c|c|c|}
\hline \multirow{2}{*}{ PAB-derivative } & \multirow{2}{*}{ Constant } & \multicolumn{2}{|c|}{ Child E. } & \multicolumn{2}{|c|}{ Infant $\mathbf{M}$. } \\
\hline & & Plate No.* & Constant & Plate No.† & Constant \\
\hline $\begin{array}{c}\text { PAH } \\
\text { PAB } \\
\text { Acetyl-PAH } \\
\text { Acetyl-PAB }\end{array}$ & $\begin{array}{l}0 \cdot 29 \\
11 \cdot 5 \\
0 \cdot 31 \\
7 \cdot 85\end{array}$ & $\begin{array}{l}24 \\
92 \\
24 \\
86\end{array}$ & $\begin{array}{l}0 \cdot 31 \\
11 \cdot 5 \\
0 \cdot 31 \\
6 \cdot 15\end{array}$ & $\begin{array}{c}22 \\
\text { PAB too low for } \\
\text { calculation } \\
19 \\
85\end{array}$ & $\begin{array}{l}0 \cdot 30 \\
0 \cdot 25 \\
8 \cdot 5\end{array}$ \\
\hline
\end{tabular}

* 100 plates.

† 95 plates. 
below that of the standards used. The lower one is diazotizable and gives an immediate Ehrlich reaction, i.e. it has a free amino group. Both react with naphthoresorcinol and aniline-diphenylamine. It is likely therefore that the lower spot $(\operatorname{Rf} 0 \cdot 28)$ is PAB-glucuronide, whereas the second from the baseline ( $R f 0.45)$, which gives a delayed reaction with Ehrlich reagent, is acetyl PAB-glucuronide. the standards. In child E.J., starting from the frontline there are two spots for acetyl-PAB $(\operatorname{Rf} 0.92)$ and free PAB ( $R f \quad 0 \cdot 83$ ). There is no acetyl-PAH present, only PAH (Rf 0.63$)$. Two spots for the glucuronyl conjugates are clearly visible $(\mathbf{R f} 0.46$ and $0 \cdot 38$ ). The two newborn infants show a different pattern. Acetyl-PAB is nearest to the front (Rf 0.92). PAB is missing or very feeble. But in

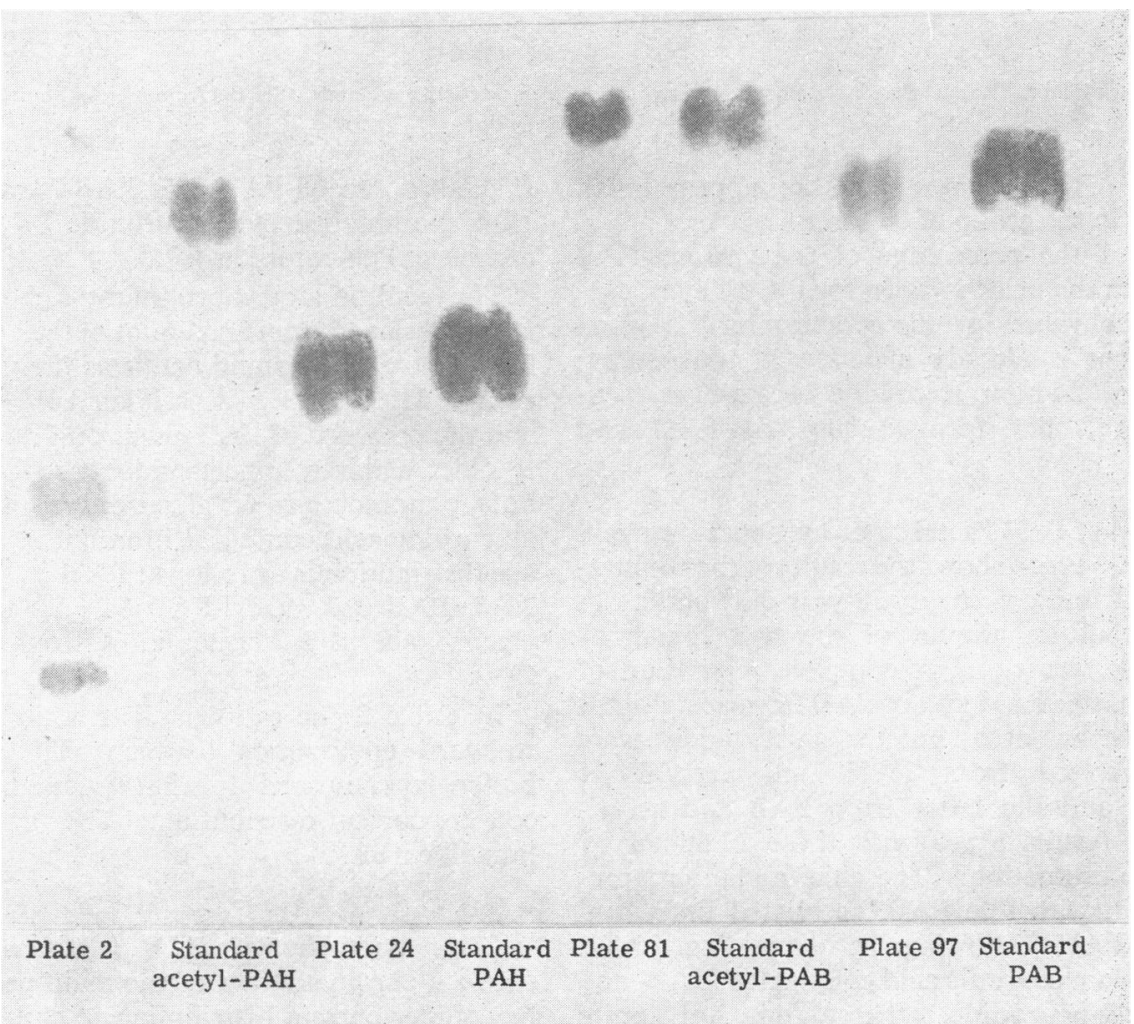

Fig. 6. - Chromatogram of the PAB metabolites separated by counter-current distribution in a child. Below the base-line the plate numbers and the different standard compounds are indicated.

In Fig. 7 the same is shown for the newborn, M.P. Here, in plate No. 2, the upper spot, acetamidobenzoyl glucuronide ( $R f 0.46$ ) is much more prominent than PAB-glucuronide ( $R f 0 \cdot 30)$. Plate No. 17 corresponds to acetyl-PAH (Rf $0 \cdot 79$ ) and 84 to acetyl-PAB (Rf 0.89). As the counter-current distribution was done on the 8- to 24-hour urine sample no detectable PAH is present.

Direct chromatography of the urine shows the same metabolites (see Fig. 8). The 0-4 hour urine sample of child, E.J., and the 4 to 8 hour sample of the infants, M.P. and L.R., are shown together with both infants there is a spot for acetyl-PAH $(\operatorname{Rf} 0 \cdot 76)$ beside the one for PAH (Rf 0.63). From the PAH glucuronides only the upper spot corresponding to acetyl-PAB glucuronide ( $\operatorname{Rf} 0.46$ ) is present.

\section{Discussion}

In children, intravenously administered $\mathrm{NaPAB}$ is rapidly cleared from the plasma mainly by conjugation with glycine, and to some extent by acetylation and glucuronidation. Nearly $50 \%$ of the administered dose is excreted as p-aminohippuric acid. 
Other important metabolites are free and acetylated PAB (about $15 \%$ each) and the glucuronides of PAB and acetyl-PAB (about $16 \%$ ). Little is excreted as acetylated PAH. This agrees with the results in human adults (Deiss and Cohen, 1950; Tabor et al., 1951), whereas in animals different proportions of the various metabolites have been found (Riggs and Christensen, 1951; Williams, 1959). of acetyl-PAB over free PAB, but also of acetyl-PAH over PAH and acetamidobenzoyl glucuronide over p-aminobenzoyl glucuronide. In accordance with previous results (Brown and Zuelzer, 1958; Vest, 1958), the extent of glucuronide formation is also lower in the newborn premature infants than later in life.

It is difficult to establish to what extent a diminish-

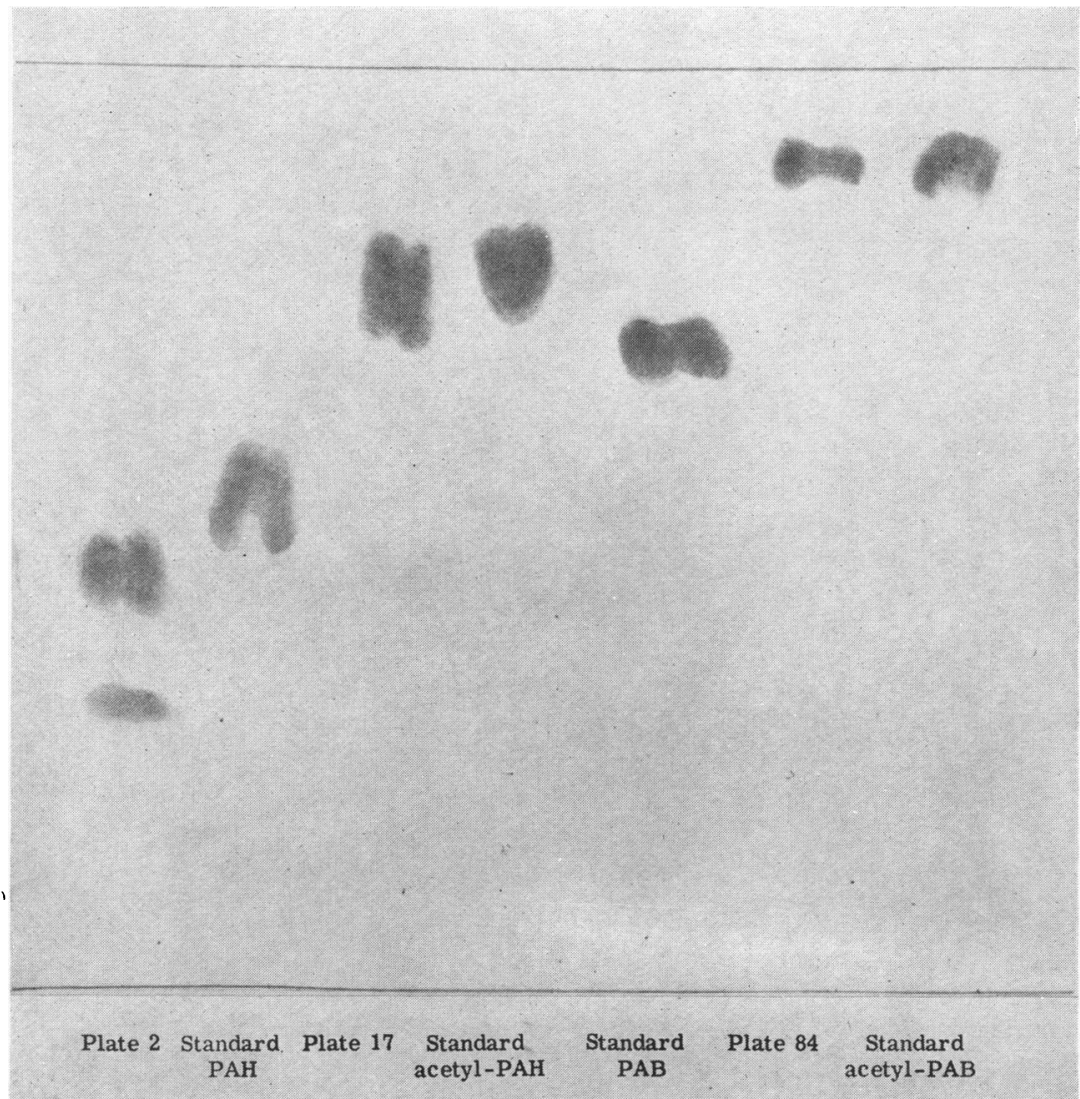

Fig. 7.-Newborn infant. Chromatogram of the PAB metabolites separated by counter-current distribution and of the standard compounds.

In newborn infants PAB disappears, more slowly from the circulation. There is diminished and delayed conjugation with glycine. This confirms the observation of Brandt (1960) who found that the activity of the hippurate synthesizing system of the liver in foetal and newborn rats is diminished. Instead of hippurate formation, acetylation at the amino group is much more prominent than in the children. This is to a certain extent at variance with the report of a limited acetylation of sulphonamides in the newborn period (Fichter and Curtis, 1955). With PAB there is, however, not only a predominance ed renal clearance of the different metabolites contributes to the lower plasma disappearance rate and the slower urinary excretion in the newborns. Clearance of the various metabolites during constant infusion of $\mathrm{NaPAB}$ was done in 3 full-term newborn infants, 3 to 8 days old and in one 12-year-old child (L. Strebel and M. Vest: unpublished results). Inulin clearance in the newborns ranged from 22 to $49 \mathrm{ml} . / \mathrm{min} . / 1 \cdot 73 \mathrm{sq} . \mathrm{m}$. It was not influenced by the infusion of NaPAB. PAH clearance amounted to 45 to $267 \mathrm{ml}$./min./1. 73 sq. m., PAB 0.8 to 23.4 ml., acetyl-PAH 34 to $154 \mathrm{ml}$., and acetyl PAB $8 \cdot 4$ to 
$105 \mathrm{ml}$. In the child the inulin clearance was 111 , PAH 535, PAB 80, acetyl PAH 260, and acetyl PAB $430 \mathrm{ml} . / \mathrm{min} . / 1 \cdot 73$ sq. $\mathrm{m}$. The low PAB clearance accounts for the small amount of free PAB excreted by the newborn infants. The predominance of the acetylated metabolites cannot, however, be explained by the clearance studies.
Every alteration of these reactions or their rate could influence the extent of hippurate formation. So it is conceivable that the glycine-condensing enzyme matures more slowly than the acetylase.

Lack of available glycine could contribute to the decreased PAH formation. Administration of $1 \mathrm{~g}$. glycine to newborn infants one hour before the

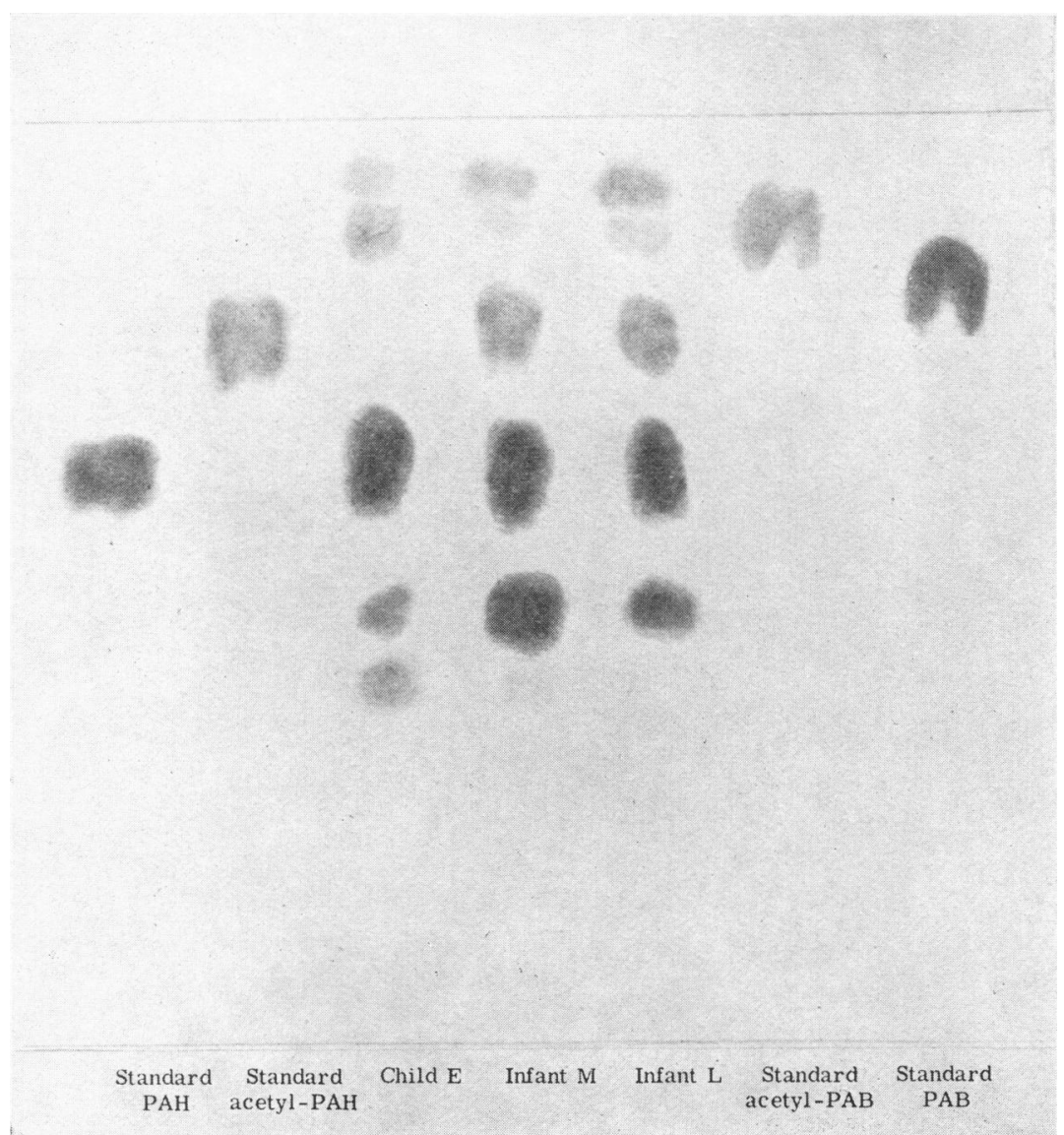

F1G. 8.-Chromatogram of urine and standard compounds in a child and two newborn infants showing the different PAB metabolites present.

The reason why acetylation is enhanced in the newborn at the expense of hippurate formation is not clear. Hippuric acid and PAH synthesis requires an activated form of benzoic acid, benzoyl co-enzyme A. The later is then able to acylate glycine (Schachter and Taggart, 1953). This reaction is catalysed by the enzyme glycine-N-acylase (Schachter and Taggart, 1954). Similarly acetylation requires the previous formation of 'active acetate', i.e. acetyl co-enzyme A. In the case of aromatic amines the acetylating enzyme is called arylamine acetylase.
PAB injection actually leads to increased PAH concentration in the plasma and to a rise in the PAH excretion in the urine as it does in adults, but PAH formation is still much inferior to that found in children (Vest and Rossier, 1963).

\section{Summary}

The metabolism of p-aminobenzoic acid (PAB) was studied by injecting a dose of $100 \mathrm{mg}$. per kg. of the sodium salt into 3 newborn premature infants, 2 full-term newborns, 2 infants 5 and 8 weeks old, 
and 4 children $8 \frac{1}{2}$ to 11 years old. In the children $\mathrm{PAB}$ is rapidly cleared from the serum, chiefly by formation of p-aminohippuric acid (PAH). The 24-hour recovery in the urine lies between 76 and $93 \%$, of which 68 to $85 \%$ are excreted within the first 4 hours. The chief conjugate in the urine is PAH, which accounts for nearly half of the total. Other metabolites are acetyl-PAB, free PAB, acetyl-PAH, PAB- and acetyl-PAB-glucuronides. In the newborn infants $\mathrm{PAB}$ is eliminated tardily from the circulation. The main conjugate formed is acetylPAB. PAH, acetyl-PAH, and free PAB are other metabolic products. The excretion in the urine is also delayed so that only about $10 \%$ of the given dose appears within the first 4 hours. The 24-hour recovery amounts to between 48 and $70 \%$. Again the major metabolite is acetylated PAB with acetylPAH, PAH, and free PAB following in decreasing order. Glucuronides account for only about $7 \%$, acetamidobenzoyl glucuronide prevailing over paminobenzoyl glucuronide. As the two older infants show, the transition from the pattern in the newborn period to that in children takes place around the 8th week of life.

\section{REFERENCES}

Brandt, I. K. (1960). Hippurate synthesis in the newborn rat. Amer. J. Dis. Child., 100, 538.

Brown, A. K., and Zuelzer, W. W. (1958). Studies on the neonatal development of the glucuronide conjugating system. J. clin. Invest., 37, 332.
Deiss, W. P., and Cohen, P. P. (1950). Studies in para-aminohippuric acid synthesis in the human: its application as a liver function test. ibid., 29, 1014.

Dische, Z. (1947). A new specific color reaction of hexuronic acids. J. biol. Chem., 167, 189.

Driscoll, S. G., and Hsia, D. Y. (1958). The development of enzyme systems during early infancy. Pediatrics, 22, 785.

Fichter, E. G., and Curtis, J. A. (1955). Sulfonamide administration in newborn and premature infants (abstract). Amer. J. Dis. Child., 90, 596.

Kretchmer, N., Levine, S. Z., McNamara, H., and Barnett, H. L. (1956). Certain aspects of tyrosine metabolism in the young. I. The development of the tyrosine oxidizing system in human liver. J. clin. Invest. 35, 236.

Riggs, T. R., and Christensen, H. N. (1951). Metabolic conjugations of $p$-aminobenzoic acid in the rat. J. biol. Chem., 193, 675 .

Schachter, D., and Taggart, J. V. (1953). Benzoyl coenzyme A and hippurate synthesis. ibid., 203, 925.

--., (1954). Glycine $N$-acylase: purification and properties. ibid., 208, 263.

Smith, H. W., Finkelstein, N., Aliminosa, L., Crawford, B., and Graber, M. (1945). The renal clearances of substituted hippuric acid derivatives and other aromatic acids in dog and man. J. clin. Invest., 24, 388.

Smith, I. (1960). Chromatographic and Electrophoretic Techniques, 2nd ed., Vol. 1. Chromatography. Heinemann, London.

Tabor, C. W., Freeman, M. V., Baily, J., and Smith, P. K. (1951). Studies on the metabolism of para-aminobenzoic acid. $J$. Pharmacol., 102, 98.

Vest, M. (1958). Insufficient glucuronide formation in the newborn and its relationship to the pathogenesis of icterus neonatorum. Arch. Dis. Childh., 33, 473.

(1959). Physiologie und Pathologie des Neugeborenenicterus. S. Karger, Basel.

- and Rossier, R. (1963). Detoxification in the newborn. Ann. N.Y. Acad. Sci., $111,183$.

Way, E. L., Smith, P. K., Howie, D. L., Weiss, R., and Swanson, R. (1948). The absorption, distribution, excretion and fate of para-aminosalicylic acid. J. Pharmacol., 93, 368.

Williams, R. T. (1959). Detoxication Mechanisms, 2nd ed. Chapman and Hall, London. 